\title{
Concentrations of polycyclic aromatic hydrocarbons in Antarctic snow polluted by research activities using snow mobiles and diesel electric generators
}

\author{
Oanh PHAM Kim¹, Kazushi NORO ${ }^{2}$, Yoshie NABESHIMA ${ }^{1}$, Tatsuya TANIGUCHI ${ }^{1}$, Yusuke FUJII ${ }^{3}$, \\ Miho ARAI $^{4}$, Toshimitsu SAKURAI ${ }^{5}$, Kenji KAWAMURA ${ }^{6}$, Hideaki MOTOYAMA ${ }^{6}$, Hien TO Thi ${ }^{7}$ \\ and Norimichi TAKENAKA ${ }^{3 *}$ \\ 1 Graduate School of Engineering, Osaka Prefecture University, 1-1 Gakuen-cho, Naka-ku, Sakai, Osaka 599-8531, Japan \\ 2 Research Institute of Environment, Agriculture and Fisheries, Osaka Prefecture, Habikino, Osaka 583-0862, Japan \\ 3 Graduate School of Humanities and Sustainable System Sciences, Osaka Prefecture University, Sakai, Osaka 599-8531, Japan \\ *takenaka@chem.osakafu-u.ac.jp \\ 4 Weathernews Inc. Mihama-ku, Chiba 261-0023, Japan \\ 5 Civil Engineering Research Institute for Cold Region, Sapporo, Hokkaido 062-8602, Japan \\ 6 National Institute of Polar Research, Tachikawa, Tokyo 190-8518, Japan \\ 7 Faculty of Environment, Vietnam National University Ho Chi Minh City, 227 Nguyen Van Cu Street, District 5, Ho Chi Minh City, Vietnam
}

(Received June 24, 2019; Revised manuscript accepted October 10, 2019)

\begin{abstract}
The polycyclic aromatic hydrocarbons (PAHs) in snow were measured in eastern Dronning Maud Land, East Antarctica. The sources of these PAHs were the snow mobiles and diesel electric generators used for scientific research from 29th December 2015 to 4th February 2016. Most of the measured PAH concentrations were low before the research campaign (lower than the detection limit or quantification limit), then increased due to the research activities, and finally decreased to a low level (lower than the quantification limit), probably because of strong blizzard winds. In addition, photolysis of the PAHs in the polluted snow samples under Antarctic conditions was investigated. The snow samples polluted by diesel electric generators were collected before and after irradiation under Antarctic sunlight (11 days); however, a decrease in PAH concentration was not observed. It was concluded that photolysis was not the main sink of the PAHs in Antarctic snow, but the occurrence of blizzard/drifting snow decreased the PAH concentration. In this paper, the preservation method for the snow samples to measure the PAHs correctly was also evaluated. To stabilize the PAHs in snow, hexane had to be added to the snow sample. Even if the snow sample was kept in a freezer, PAHs evaporated without hexane.
\end{abstract}

Key words: Polycyclic aromatic hydrocarbons, Antarctica, Photolysis, Blizzard

\section{Introduction}

Polycyclic aromatic hydrocarbons (PAHs) are toxic organic pollutants found in snow, even in remote areas (Masclet et al., 2000; Carrera et al., 2001; Gouin et al., 2010; Gabrieli et al., 2010). As the byproducts of incomplete combustion of fossil fuels, PAHs are mainly emitted from anthropogenic sources, especially from diesel engines such as vehicles and electric generators, coal combustion and wood combustion (Hautala et al., 1995; Grabieli et al., 2010; Finlayson-Pitts and Pitts, 1997; Li et al., 2006; Yu et al., 2014). Atmospheric PAHs in the form of particles can travel far from their original sources, reaching isolated areas as depositions on snow surfaces or nuclei of precipitation (Welch et al., 1991; Masclet et al., 2000; Gabrieli et al., 2010; Gouin et al., 2010; Hayakawa et al., 2019). Moreover, PAHs have been a concern because of their carcinogenic and mutagenic properties to human health (Rianawati and Balasubramanian, 2009; Liu et al., 2006) and ecology (Na et al., 2011). Although the health risk assessment of PAHs in snow has not been considered, the PAHs in snow should be monitored.

In the 20th century, the PAHs in the surface snow of Antarctica were reported to be below the detection limit (Risebrough et al., 1976; Tanabe et al., 1983). However, recent studies have shown that PAHs have become more abundant. Desideri et al. reported 5 PAH concentrations from $12-94 \mathrm{ng} \mathrm{kg}^{-1}$ in 8 surface Antarctic snow samples and 6 PAHs at concentrations of $18-99 \mathrm{ng} \mathrm{kg}^{-1}$ in snow samples at different depths $(-2 \mathrm{~m},-1 \mathrm{~m}$ and surface, Desideri et al., 1994). In a snow pit on the Ekström Shelf Ice in the Weddell Sea, the PAH concentrations were 26$197 \mathrm{ng} \mathrm{kg}^{-1}$, and the distance to the sources (ships and research stations) in this region had the main impact on the snow PAH concentrations (Kukučka et al., 2010). A 
total of $14 \mathrm{PAH}$ concentrations of $0.7 \mathrm{ng} \mathrm{kg}^{-1}$ in deep firn samples and $3.4 \mathrm{ng} \mathrm{kg}^{-1}$ in surface snow were reported by Fuoco et al. (Fuoco et al., 2012). Vecchiato reported 16 PAHs in snow at concentration of $0.65-140 \mathrm{ng} \mathrm{kg}^{-1}$ in the coastal region of Antarctica, and the source was estimated to be mostly a local source in Antarctica but not from another continent (Vecchiato et al., 2015). Generally, the total PAH concentration was expected to be zero to several $\mathrm{ng} \mathrm{kg}^{-1}$ in clean snow and old snow and several tens of $\mathrm{ng} \mathrm{kg}^{-1}$ in polluted snow near stations in Antarctica. Although there are some reports on PAHs in snow and ice in the Antarctic, the data are limited and scarce.

The preservation method of snow samples for PAH analysis has not been properly studied since samples were usually transferred to the laboratory in the frozen state until analysis. In a previous study, the PAHs in rain samples were reported to be absorbed onto plastic materials, and therefore, glass or metal bottles should be used for preservation of the PAHs in rain (Thang et al., 2014). Furthermore, a preservation method for the PAHs in snow was also reported. The PAHs in aqueous samples were absorbed onto organic materials and evaporated into the gas phase. Thus, to preserve PAHs stably, organic solvents must be added to the sampling bottle.

An investigation was conducted in eastern Dronning Maud Land, East Antarctica from 29 December 2015 to 4 February 2016 (JARE57) to measure the nitrogen species in the atmosphere and in snow and core drilling samples. PAHs had been emitted from snow mobiles and had been deposited on snow. Moreover, for research and general purposes, several electric generators were used near the research area, and PAHs were expected to contaminate the nearby snow. It is very important to investigate the extent of pollution in the Antarctic snow from the exhaust gas of diesel electric generators due to the research activities in Antarctica. In this paper, the variation in $\mathrm{PAH}$ concentration due to research in Antarctica for approximately one month was reported. In addition, the sampling and preservation methods for the PAHs in snow were also investigated again and described.

\section{Sampling and Methods}

\subsection{Sampling point and expected source of PAHs}

Japan organized a research campaign called the 57th Japanese Antarctic Research Expedition (JARE57) from December 2015 to April 2017. The present study was conducted in the summer research period of JARE57 from 29th December 2015 to 4th February 2016. The sampling points were in eastern Dronning Maud Land, East Antarctica, approximately $1 \mathrm{~km}$ on the downwind side $\left(\mathrm{S} 69.40^{\circ}, \mathrm{E} 41.55^{\circ}\right)$ of the katabatic wind from the H128 point, named by the Japanese Antarctic Research Expedition based on the point number on the travel route from Showa Station to the Antarctic inland. Snow mobiles are the main means of transport in Antarctica, which run a few times or less frequently per year near the H128 point. Moreover, for the transportation of the JARE57 researchers, three snow mobiles were brought to the research area. These snow mobiles were SM100S-type snow mobiles produced by Ohara Corporation in NagaokaCity, Niigata, Japan, and used diesel oil as their fuel. The SM114, SM115 and SM117 snow mobiles were produced in 2002, 2003 and 2013, respectively. In addition, the diesel engines of the SM114 and SM115 snowmobiles were from Komatsu Ltd., type SA6D125, with an output power of $220 \mathrm{~kW}$ and an engine displacement of 11.04 liter and that for SM117 was from Scania Ltd., type DC13, with an output power of $257 \mathrm{~kW}$ and an engine displacement of 12.7 liter, respectively. One of the snow mobiles (SM115) operated its engine approximately 6-8 hours per day, and the other two (SM114 and SM117) ran their engines approximately 4 hours per day for everyday maintenance. In addition, a YDG250-E Yanmar diesel electric generator (output power of $2.0 \mathrm{~kW}$ and displacement volume of 0.211 liter) was used for 10-12 hours per day for research activities; another generator (Yanmar YDG200 with an output power of $1.7 \mathrm{~kW}$ and a displacement volume of 0.199 liter) was used for life support approximately 6 hours per day; two gasoline electric generators (a Yamaha EF2500i with an output power of $2.5 \mathrm{~kW}$ and displacement volume of 0.171 liter and a Honda ET4500 with an output power of $4.0 \mathrm{~kW}$ and displacement volume of 0.389 liter) were used for core drilling approximately 12 hours per day. Special fuel for use in Antarctica with a low freezing temperature (freezing point $<-60{ }^{\circ} \mathrm{C}$ ) was used for the diesel electric generators and snow mobiles. Briefly, the 3 snow mobiles and 2 diesel electric generators were expected to be important sources of PAHs. The positional relationships of the snowmobiles, electric generators and sampling points are shown in Fig. 1.

\section{Main direction of katabatic wind}

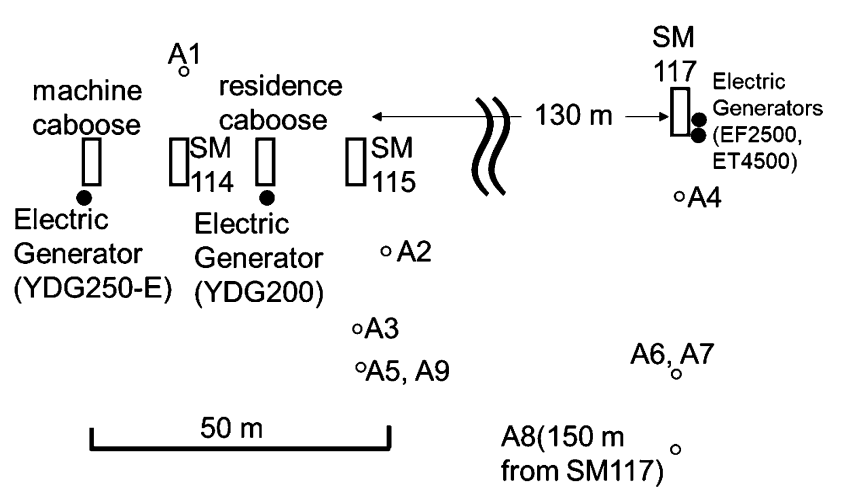

Fig. 1. Positional relationships of the snowmobiles, electric generators and sampling points : Sampling points A1-A9, see Table 1.

: Electric generator, see text. Longitude latitude: residence caboose: $69.400592 \mathrm{~S}$, 41.545026E; SM117: 69.401691S, 41.547142E. 


\subsection{The PAHs analyzed and reagents}

Twelve PAHs with 3 to 6 aromatic rings were selected to characterize the Antarctica snow samples. These PAHs were phenanthrene (Phe), anthracene (AnT), fluoranthene (Fluo), pyrene (Pyr), benz $[a]$ anthracene (BaA), chrysene (Chr), benzo[b]fluoranthene $(\mathrm{BbF})$, benzo[k] fluoranthene $(\mathrm{BkF})$, benzo $[a]$ pyrene $(\mathrm{BaP})$, dibenz $[a, h]$ anthracene (DahA), indeno[1,2,3-cd]pyrene (IndP) and benzo[ghi]perylene (BghiP). Phe and AnT are 3-ring PAHs, Fluo, Pyr, BaA, and Chr are 4-ring PAHs, BbF, $\mathrm{BkF}, \mathrm{BaP}$, and DahA are 5-ring PAHs and IndP and BghiP are 6-ring PAHs. The PAHs were analyzed according to the literature (Thang et al., 2014). In brief, a high-performance liquid chromatography (HPLC) instrument coupled with a fluorescence detector (JASCOFP 2020 plus) was utilized, and the injection volume was $50 \mu \mathrm{L}$. An Inertsil HPLC column, ODS-P-5- $\mu \mathrm{m} 3 \times$ $250 \mathrm{~mm}$, was used, and the mobile phase was a mixture of $\mathrm{MeOH} / \mathrm{H}_{2} \mathrm{O}(3 / 1, \mathrm{v} / \mathrm{v})$ at a mobile phase flow rate of $0.7 \mathrm{~mL} \mathrm{~min}^{-1}$. The excitation and emission wavelengths were $270 \mathrm{~nm}$ and $410 \mathrm{~nm}$, respectively, from 0-45 minutes and $300 \mathrm{~nm}$ and $500 \mathrm{~nm}$, respectively, from 45-60 minutes. All solvents and chemicals used were obtained from Wako Chemical Ind., Ltd., and were of HPLC grade or reagent grade quality and used as received. The PAH standards were purchased from Supelco Standard Chemical. The pure water was prepared by a Merck Millipore Inc. Direct-Q 3UV (resistivity $\geq 18.2 \mathrm{M} \Omega \mathrm{cm}$ ).

\subsection{Sampling and preservation methods of the PAHs}

Surface snow to a depth of less than $1 \mathrm{~cm}$ was collected with a stainless-steel snow scoop and kept in 1 liter glass bottles. Before closing the cap of the bottle, $100 \mathrm{~cm}^{3}$ hexane was added to each bottle, and aluminum foil was placed between the glass bottle and the polypropylene cap. The snow sample collected in Antarctica was kept below the freezing point and was not thawed until analysis. The snow samples collected in Japan thawed during transport to the laboratory at room temperature and kept in a refrigerator at approximately $4{ }^{\circ} \mathrm{C}$ until analysis.

\subsection{Photo decomposition of the PAHs in the polluted snow samples from Antarctica}

The surface snow near the diesel electric generator was polluted by exhaust gas and had turned dark gray. The polluted snow was collected on 16 January 2016 and mixed via the quartering method, which is generally used for soil sampling. Then, an aliquot of the sample was collected for analysis. The remainder of the sample was then placed on a clean snow surface in the upwind area of the katabatic wind from the diesel electric generator to minimize the influence of newly emitted pollutants. On 27 January 2016, an aliquot of the irradiated sample by natural sunlight was collected for analysis. On 25 January, the first sunset in 2016 occurred; therefore, sunlight was observed for almost the entire period.

\subsection{Measurement of the wind speed}

The wind speeds and directions were measured every day in the morning (approximately $6 \mathrm{AM}$ ), noon (approximately $12 \mathrm{PM}$ ) and evening (approximately 19 PM) from 29th December 2015 to 4th February 2016 by a Kestrel 4500 pocket weather tracker. Furthermore, the wind speeds and directions were also monitored with an aerovane (model-15130, Young Co., USA) at an automated weather station near the sampling point.

\section{Results and discussions}

\subsection{Sampling and preservation methods of the PAHs}

The thawing and storage conditions of the snow samples for the PAH measurements have already been reported (Thang et al., 2014): 1) plastic and Teflon bottles cannot be used as storage bottles for PAHs due to their absorption onto these materials, and 2) hexane must be added to the snow sample before thawing to prevent $\mathrm{PAH}$ evaporation. The snow/ice samples from Antarctica are usually transported to Japan without thawing, but in anticipation of any trouble during transportation, it is required to investigate the storage method for PAHs. Figure 2 shows one example of the comparison of the $\mathrm{PAH}$ concentrations in snow in cases where hexane was added or not added to the snow. Phe and AnT were not analyzed here. The sample had thawed during transportation from the sampling point to the laboratory. Although the sample bottle was tightly closed with a screw cap, a portion of the PAHs evaporated from the sample. It is speculated that if hexane is added before thawing, the PAHs are dissolved in hexane, but if hexane is not present, the PAHs in the sample evaporate into the gas phase. The evaporation of PAHs without hexane could occur because of the hydrophobicity of volatile PAHs. Generally, PAHs with smaller molecules evaporate more efficiently than those with heavier molecules when hexane was not added.

The importance of the timing of the addition of hexane is displayed in Fig. 3 with 3 cases. The sample was collected on 26 January at the Asia Center for Air Pollution Research (ACAP), and only one sample was collected for each case. Case 1 indicated that the snow was collected via thawing with a warmed funnel at $10{ }^{\circ} \mathrm{C}$, and the thawed sample was immediately collected in a bottle with hexane. For only a few seconds, the sample was an aqueous solution without hexane. Case 2 indicated that the snow was collected directly into hexane and then thawed in the storage bottle. Finally, case 3 indicated that the snow was collected without hexane; then, after the sample had completely thawed in the bottle, hexane was immediately added to the sample bottle. Although the time as an aqueous solution without hexane was short (case 1), some of the PAHs were lost. The time as an aqueous solution without hexane in case 3 was longer than that in case 1 , and more of the PAHs were lost from the sample, as expected. Compared with the result in Fig. 


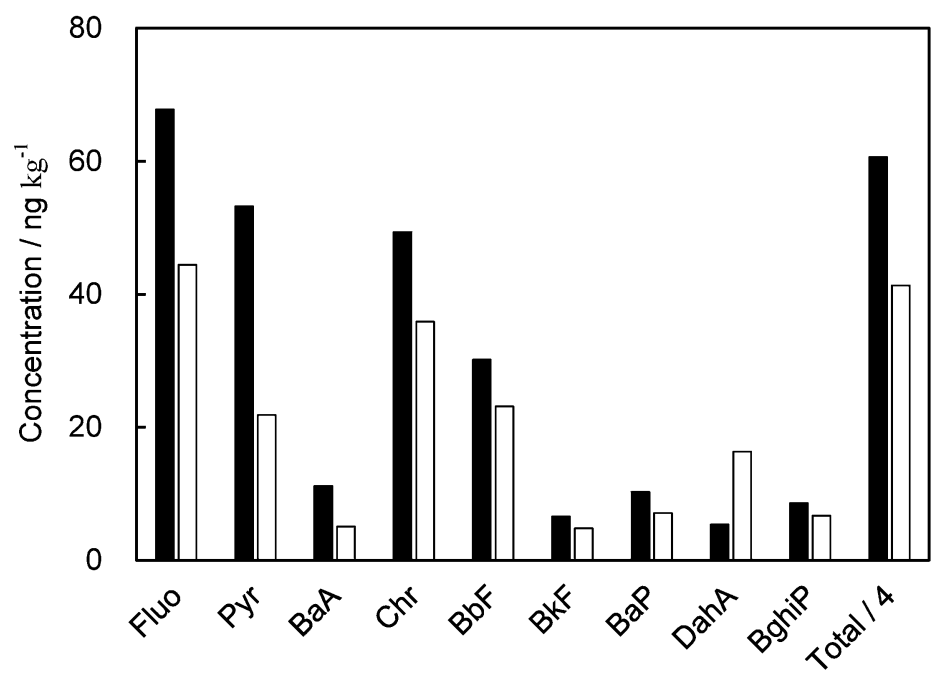

Fig. 2. PAH concentrations in the snow sample with and without the addition of hexane when the snow sample was collected. The snow was collected in Gifu on 18 January 2009 (G1 in Table 1).

- Hexane was added to the snow sample, and the sample was transferred to the laboratory. $\square$ Sample was transferred to the laboratory without adding hexane.

Both snow samples were thawed before being transferred to the cooler $\left(4^{\circ} \mathrm{C}\right)$ in the laboratory.

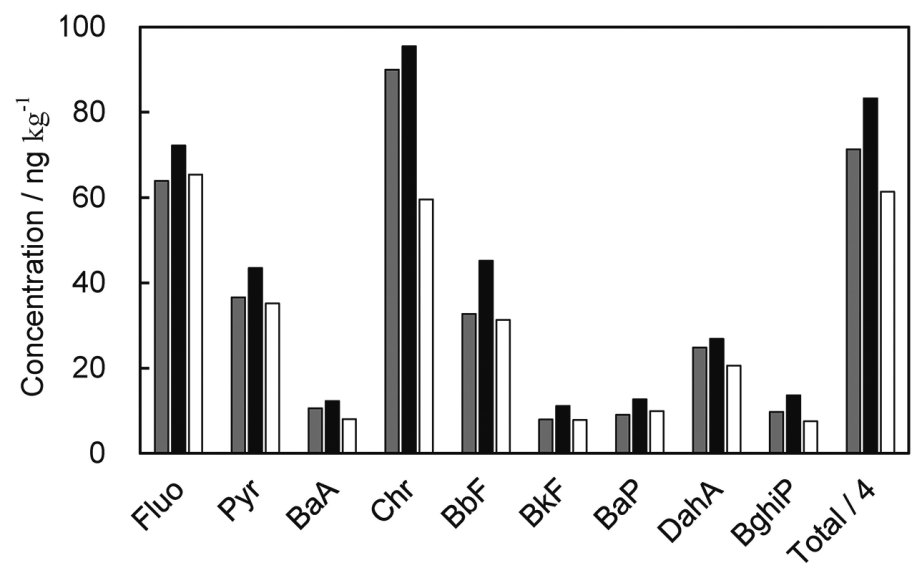

Fig. 3. PAH concentrations in the snow samples obtained by the three sampling and thawing methods. The sample was collected on 26 January 2009 at ACAP.

$\square$ Snow sampled with thawing at $10^{\circ} \mathrm{C}$ and collected in hexane.

- Snow sampled directly in hexane, and then thawed.

$\square$ Snow sampled without hexane, and hexane was added immediately after completely thawing.

2 , the amounts of evaporation loss were smaller due to the shorter time with no hexane, and therefore, it is considered that the difference between the lighter and heavier molecules was not very large. As shown by the results in Figs. 2 and 3, PAHs are easily evaporated from the sample without hexane in a short time and from a tightly closed bottle. Therefore, for the measurement of the PAHs in snow, hexane must be added to the sampling bottle before transport.

\subsection{Variation in the PAH concentration in the snow due} to the research activities in Antarctica

To assist the research activities, electric generators or electric engines were brought to Antarctica and operated during the research campaign. Due to the usage of diesel electric generators, exhaust gas, including particles, were emitted into the clean air and snow, and gaseous and particulate PAHs were assumed to be deposited on clean snow in Antarctica. The snow samples were collected before and after the JARE57 research campaign in Antarctica, and the change in PAH concentration in the snow was investigated.

Figure 4 and Table 1 show the 8 PAH concentrations in the snow measured at several locations in Japan compared with those in the Antarctica snow collected before the JARE57 research campaign. In Fig. 4, Phe was not included in Antarctica since those PAHs were not analyzed in the snow collected in Japan. The total PAH concentrations were $92.3-881.2 \mathrm{ng} \mathrm{kg}^{-1}$ in Japan and 4.0$7.2 \mathrm{ng} \mathrm{kg}^{-1}$ in Antarctica. The PAH concentrations in Antarctica were low and comparable to the levels reported in other studies. The concentrations of PAHs containing 


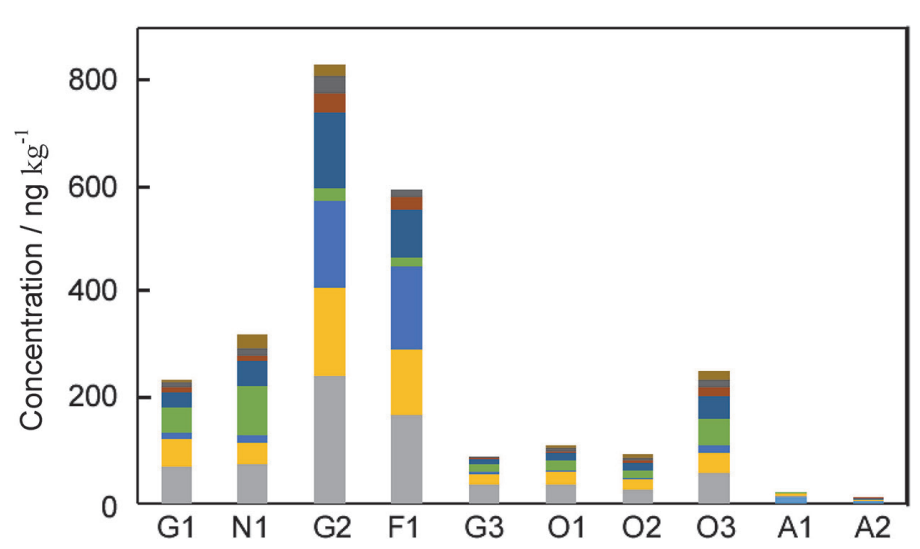

Fig. 4. Comparison between the PAHs in the snow samples collected in Japan and Antarctica Fluo, $\square$ Pyr, $\square \mathrm{BaA}, \square \mathrm{Chr}, \mathrm{BbF}, \mathbf{B k F}, \square \mathrm{BaP}, \square \mathrm{DahA}$

G1, N2, G2, F1, G3, O1, O2 and O3 are the results in Japan, and A1 and A2 are the fresh snow samples before the research activities in Antarctica. Details are shown in Table 1.

more than 5 rings in the Antarctic snow were lower than the detection limits (defined as $\mathrm{S} / \mathrm{N}=3$ ) before the research campaign. The sampling point was in an area approximately $1 \mathrm{~km}$ downwind of the travel route to inland Antarctica. The presence of PAHs in the background snow was expected to be from the occasional snow mobiles that passed the H128 point a few times or less frequently a year and from the snow mobiles that were brought to the research area.

Figure 5 shows the PAH concentrations in the snow collected in Antarctica, including Phe. In all samples, the concentrations of AnT, DahA and IndP were lower than the detection limit, which was defined as 3 times the standard deviation. Snow samples A1 and A2 were collected on 29 December 2015, 140 minutes after the snow mobiles reached the sampling area, $30 \mathrm{~m}$ away from the snow mobiles in the upwind and downwind directions, respectively. From Fig. 5, it can be confirmed that the snow might not be affected by snow mobiles in this research since the concentrations of PAHs were very low and those of the upwind location were slightly higher than those of the downwind location. From Table 1, only the Phe and Pyr concentrations were higher than the quantification limits, which were defined as 10 times the standard deviation $(\mathrm{S} / \mathrm{N}=10)$. In the $\mathrm{A} 1$ and $\mathrm{A} 2$ samples, six-ring PAHs were not observed, and the concentrations of five-ring PAHs were lower than the quantification limits or determination limits. Snow samples A3 and A4 were collected after 10 days on the downwind side of the snow mobiles; therefore, the concentrations of PAHs were expected to have increased. As shown in Fig. 5, the concentration of higher-ring PAHs, which was not detected in A1 and A2, increased remarkably. This phenomenon means that the research activities were the cause of these PAHs. The snow sample of A3 was collected 25 meters downwind from the snow mobiles and that of A4 was collected 10 meters downwind. Therefore, the total PAH concentration of A4 was higher than that of A3. A5 and A6 were collected after 18 days
(16 January). The concentrations of higher-ring PAHs increased in both snow samples, but the total PAH concentrations were lower than those of A3 and A4. The contribution from higher-ring PAHs increased during the research period, but it is speculated that some of the snow was blown away by several snowdrift or blizzard events from 8-9 and from 12-13 January 2016, at wind speeds higher than $10 \mathrm{~m} \mathrm{~s}^{-1}$ (Motoyama and Hirasawa, 2018). Furthermore, the concentrations of total PAHs in A7 collected after almost one month of research (27 January) had decreased more due to a strong blizzard event from 18-20 January 2016 (Motoyama and Hirasawa, 2018). During the research period, snow fell twice and only in small amounts, which eliminated the effect from newly fallen snow. Samples A8 and A9 were collected on 27 January 2016. However, the hexane phase was not found in those samples when the bottles were opened for analysis, and the reason was not clear. The concentrations of PAHs were very low, and the PAHs with smaller molecules had completely disappeared. From this result, it was confirmed that if hexane was not added to the storage bottle, and even if the sample had not thawed during storage period, some of the PAHs, especially the lower molecule weight PAHs, evaporated.

\subsection{Decomposition of the PAHs by solar radiation in Antarctica}

To our knowledge, this study was the first time that photolysis of PAHs was investigated in a real snow sample under real environmental conditions. When electric generators were used for JARE57 in Antarctica, exhaust gas including particles was emitted into clean snow, thus, the snow near the generator turned dark gray. It was expected that in the dark gray snow area, high concentrations of PAHs would be encountered. In addition, the UV light in Antarctica is very strong, which was assumed to accelerate the photolysis of PAHs. For this reason, polluted snow was collected soon after initial pollution by the diesel electric generator, and the polluted 
Table 1. PAHs concentrations in snow obtained in Antarctica and Japan

\begin{tabular}{|c|c|c|c|c|c|c|c|c|c|c|c|c|c|c|c|c|c|c|}
\hline \multirow{2}{*}{ No. } & \multirow{2}{*}{$\begin{array}{r}\text { Sampling } \\
\text { date }\end{array}$} & \multirow{2}{*}{\multicolumn{2}{|c|}{ Place }} & \multirow{2}{*}{ Snow sample } & \multirow{2}{*}{$\begin{array}{l}\text { Sample } \\
\text { Volume } \\
\text { / mL }\end{array}$} & \multicolumn{12}{|c|}{ PAHs concentration $/ \mathrm{ng} \mathrm{kg}^{-1}$} & \multirow{2}{*}{ Note $^{*}$} \\
\hline & & & & & & Phe & AnT & Fluo & Pyr & $\mathrm{BaA}$ & $\mathrm{Chr}$ & $\mathrm{BbF}$ & $\mathrm{BkF}$ & $\mathrm{BaP}$ & DahA & IndP & BghiP & \\
\hline $\mathrm{A} 1$ & \multirow{2}{*}{$\begin{array}{r}29 \text { Dec., } \\
2015\end{array}$} & \multirow{2}{*}{\multicolumn{2}{|c|}{$\begin{array}{c}\text { Antarctica } \\
\text { H128, just } \\
\text { arrived }\end{array}$}} & \multirow{2}{*}{$\begin{array}{c}\text { Upwind of SM114 } \\
\text { Downwind of SM115 }\end{array}$} & 358 & 13.4 & ND & $\underline{2.0}$ & 3.7 & $\underline{0.2}$ & $\underline{1.3}$ & ND & ND & ND & ND & ND & --- & \\
\hline $\mathrm{A} 2$ & & & & & 510 & 4.4 & $\mathrm{ND}$ & ND & 2.6 & $\underline{0.1}$ & ND & $\underline{1.1}$ & $\underline{0.2}$ & ND & ND & ND & --- & \\
\hline $\mathrm{A} 3$ & \multirow[t]{2}{*}{$\begin{array}{r}08 \text { Jan., } \\
2016\end{array}$} & \multirow{2}{*}{\multicolumn{2}{|c|}{$\begin{array}{c}\text { Antarctica } \\
\text { H128, } 10 \\
\text { days }\end{array}$}} & $\begin{array}{l}25 \text { meters downwind } \\
\text { from SM115 }\end{array}$ & 500 & 10.4 & $\mathrm{ND}$ & 4.3 & 5.0 & $\underline{0.2}$ & 1.7 & 2.4 & 0.6 & $\underline{0.8}$ & ND & ND & --- & \\
\hline A4 & & & & $\begin{array}{l}10 \text { meters downwind } \\
\text { from SM117 }\end{array}$ & 515 & 19.2 & ND & 10.1 & 14.5 & $\underline{0.2}$ & 2.5 & 2.3 & 0.5 & 0.9 & ND & ND & --- & \\
\hline A5 & \multirow[t]{2}{*}{$\begin{array}{r}16 \text { Jan., } \\
2016\end{array}$} & \multirow{2}{*}{\multicolumn{2}{|c|}{$\begin{array}{c}\text { Antarctica } \\
\text { H128, } 18 \\
\text { days }\end{array}$}} & $\begin{array}{l}30 \text { meters downwind } \\
\text { from SM115 }\end{array}$ & 510 & 10.4 & ND & 11.3 & 7.2 & 0.8 & 2.9 & 4.6 & 1.6 & 2.7 & ND & ND & --- & \\
\hline A6 & & & & $\begin{array}{l}40 \text { meters downwind } \\
\text { from SM117 }\end{array}$ & 465 & 6.8 & ND & $\underline{2.7}$ & 1.9 & $\underline{0.2}$ & $\underline{0.8}$ & $\underline{1.6}$ & $\underline{0.4}$ & $\underline{0.6}$ & ND & ND & --- & \\
\hline A7 & \multirow[t]{3}{*}{$\begin{array}{r}27 \text { Jan., } \\
2016\end{array}$} & \multirow{3}{*}{\multicolumn{2}{|c|}{$\begin{array}{c}\text { Antarctica } \\
\text { H128, } \\
\text { 29days }\end{array}$}} & $\begin{array}{l}40 \text { meters downwind } \\
\text { fromSM117 }\end{array}$ & 410 & $\underline{4.3}$ & ND & $\underline{3.0}$ & 2.6 & $\underline{0.2}$ & $\underline{0.7}$ & $\underline{1.7}$ & $\underline{0.3}$ & ND & ND & ND & --- & \\
\hline A8 & & & & $\begin{array}{l}150 \text { meters downwind } \\
\text { from SM117 }\end{array}$ & 365 & ND & ND & ND & 4.4 & ND & $\underline{0.8}$ & ND & ND & ND & ND & ND & --- & No Hx \\
\hline A9 & & & & $\begin{array}{l}30 \text { meters downwind } \\
\text { from SM115 }\end{array}$ & 340 & ND & $\mathrm{ND}$ & ND & 4.6 & $\underline{0.2}$ & $\underline{0.9}$ & $\underline{1.8}$ & $\underline{0.3}$ & $\underline{0.6}$ & ND & ND & --- & No $\mathrm{Hx}$ \\
\hline ADI1 & \multirow[t]{3}{*}{$\begin{array}{r}16 \text { Jan., } \\
2016\end{array}$} & \multirow{3}{*}{\multicolumn{2}{|c|}{$\begin{array}{l}\text { Antarctica } \\
\text { H128 }\end{array}$}} & $\begin{array}{l}\text { polluted snow before } \\
\text { irradiation }\end{array}$ & 550 & $\begin{array}{l}8.80 \\
\times 10^{5}\end{array}$ & $\mathrm{ND}$ & $\begin{array}{l}8.75 \\
\times 10^{4}\end{array}$ & $\begin{array}{l}2.41 \\
\times 10^{4}\end{array}$ & $\begin{array}{r}1.31 \\
\times 10^{2}\end{array}$ & $\begin{array}{r}8.50 \\
\times 10^{2}\end{array}$ & ND & ND & ND & ND & ND & --- & \\
\hline ADI2 & & & & & 530 & $\begin{array}{l}1.02 \\
\times 10^{6}\end{array}$ & ND & $\begin{array}{l}1.01 \\
\times 10^{6}\end{array}$ & $\begin{array}{l}2.39 \\
\times 10^{6}\end{array}$ & $\begin{array}{r}1.38 \\
\times 10^{2}\end{array}$ & $\begin{array}{l}1.01 \\
\times 10^{3}\end{array}$ & $\mathrm{ND}$ & ND & ND & ND & ND & --- & \\
\hline ADIav & & & & Average & --- & $\begin{array}{r}9.48 \\
\times 10^{5} \\
\end{array}$ & ND & $\begin{array}{l}9.44 \\
\times 10^{4}\end{array}$ & $\begin{array}{r}2.40 \\
\times 104 \\
\end{array}$ & $\begin{array}{r}1.35 \\
\times 10^{2} \\
\end{array}$ & $\begin{array}{r}9.29 \\
\times 10^{2} \\
\end{array}$ & $\mathrm{ND}$ & ND & ND & ND & ND & --- & \\
\hline ADF1 & \multirow[t]{3}{*}{$\begin{array}{r}27 \text { Jan., } \\
2016\end{array}$} & \multirow{3}{*}{\multicolumn{2}{|c|}{$\begin{array}{c}\text { Antarctica } \\
\text { H128 }\end{array}$}} & $\begin{array}{l}\text { polluted snow after } 11 \\
\text { days irradiation }\end{array}$ & 474 & $\begin{array}{r}1.09 \\
\times 10^{6}\end{array}$ & ND & $\begin{array}{l}1.14 \\
\times 10^{6}\end{array}$ & $\begin{array}{l}2.77 \\
\times 10^{6}\end{array}$ & $\begin{array}{r}1.42 \\
\times 10^{2}\end{array}$ & $\begin{array}{l}1.23 \\
\times 10^{3}\end{array}$ & ND & ND & ND & ND & ND & --- & \\
\hline ADF2 & & & & & 500 & $\begin{array}{l}7.06 \\
\times 10^{5}\end{array}$ & ND & $\begin{array}{l}7.88 \\
\times 10^{4}\end{array}$ & $\begin{array}{l}2.02 \\
\times 10^{4}\end{array}$ & $\begin{array}{r}1.26 \\
\times 10^{2}\end{array}$ & $\begin{array}{r}8.59 \\
\times 10^{2}\end{array}$ & ND & 155 & ND & ND & ND & --- & \\
\hline ADFav & & & & Average & -- & $\begin{array}{r}9.46 \\
\times 10^{5} \\
\end{array}$ & ND & $\begin{array}{r}9.62 \\
\times 10^{4} \\
\end{array}$ & $\begin{array}{r}2.39 \\
\times 10^{4}\end{array}$ & $\begin{array}{r}1.34 \\
\times 10^{2} \\
\end{array}$ & $\begin{array}{r}1.04 \\
\times 10^{3} \\
\end{array}$ & ND & 77.7 & ND & ND & ND & --- & \\
\hline \multirow[t]{2}{*}{ G1 } & \multirow{2}{*}{\multicolumn{2}{|c|}{18 Jan., 2009}} & \multirow{2}{*}{$\begin{array}{c}\text { Gifu } \\
\text { Pref., Ski } \\
\text { area }\end{array}$} & Fresh snow & 360 & --- & -- & 67.8 & 53.2 & 11.2 & 49.4 & 30.2 & 6.6 & 10.3 & 5.4 & --- & 8.6 & \\
\hline & & & & & 455 & -- & -- & 44.4 & 21.8 & 5.1 & 35.9 & 23.1 & 4.8 & 7.1 & 16.3 & -- & 6.7 & No Hx \\
\hline \multirow[t]{2}{*}{$\mathrm{N} 1$} & 26 Jan. & 2009 & $\begin{array}{l}\text { Niigata } \\
\text { Pref. }\end{array}$ & $\begin{array}{l}\text { freshly-fallen } \\
\text { snow }\end{array}$ & 3313 & --- & -- & 72.2 & 43.5 & 12.3 & 95.5 & 45.2 & 11.1 & 12.7 & 26.9 & --- & 13.6 & \\
\hline & & & $\mathrm{AC}$ & & 2898 & $\ldots$ & $\ldots$ & 65.4 & 35.2 & 8.0 & 59.6 & 31.3 & 7.9 & 9.9 & 20.6 & --- & 7.5 & No $\mathrm{Hx}$ \\
\hline G2 & $16 \mathrm{Jan}$. & 2010 & $\begin{array}{c}\text { Gifu } \\
\text { Pref. Ski }\end{array}$ & $\begin{array}{l}\text { Fresh snow } \\
\text { cover }\end{array}$ & 209 & --- & -- & 240.2 & 168.7 & 164.2 & 24.6 & 142.2 & 36.1 & 32.9 & 20.5 & --- & 51.8 & \\
\hline & & & & & 198 & --- & --- & 147.6 & 97.6 & 63.3 & 9.4 & 33.3 & 7.5 & 6.6 & ND & --- & 9.0 & No Hx \\
\hline F1 & 11 Mar. & 2010 & $\begin{array}{c}\text { Fukui } \\
\text { Pref., rice }\end{array}$ & $\begin{array}{l}\text { Fresh snow } \\
\text { cover }\end{array}$ & 694 & -- & -- & 167.3 & 122.6 & 159.2 & 16.2 & 89.1 & 25.4 & 15.4 & ND & -- & 31.8 & \\
\hline & & & field & & 636 & --- & -- & 106.6 & 71.4 & 66.4 & 6.8 & 23.5 & 6.3 & 5.3 & ND & -- & 3.2 & No $\mathrm{Hx}$ \\
\hline G3 & 14 Jan. & 2011 & $\begin{array}{l}\text { Gifu } \\
\text { Pref., Ski } \\
\text { area }\end{array}$ & $\begin{array}{l}\text { Fresh snow } \\
\text { cover }\end{array}$ & 705 & --- & --- & 34.9 & 20.1 & 3.6 & 14.4 & 10.0 & 3.4 & 2.6 & ND & --- & 3.2 & \\
\hline 01 & $11 \mathrm{Feb}$. & 2011 & $\begin{array}{l}\text { Osaka } \\
\text { Perf., Mt. } \\
\text { Ikoma }\end{array}$ & $\begin{array}{l}\text { Fresh snow } \\
\text { cover }\end{array}$ & 934 & --- & --- & 35.6 & 23.0 & 5.1 & 17.0 & 14.3 & 4.7 & 4.6 & 4.6 & --- & 5.8 & \\
\hline $\mathrm{O} 2$ & $14 \mathrm{Feb}$ & 2011 & $\begin{array}{l}\text { Osaka } \\
\text { Perf., Mt. } \\
\text { Ikoma }\end{array}$ & $\begin{array}{l}\text { Fresh snow } \\
\text { cover }\end{array}$ & 708 & --- & --- & 26.6 & 17.9 & 4.3 & 14.3 & 13.0 & 4.5 & 4.8 & 7.5 & --- & 6.9 & \\
\hline $\mathrm{O} 3$ & $15 \mathrm{Feb}$. & 2011 & $\begin{array}{l}\text { Osaka } \\
\text { Perf., Mt. } \\
\text { Ikoma }\end{array}$ & $\begin{array}{l}\text { freshly-fallen } \\
\text { snow }\end{array}$ & 699 & --- & --- & 56.0 & 38.5 & 13.8 & 50.2 & 44.1 & 15.4 & 16.4 & 17.0 & --- & 27.6 & \\
\hline $\mathrm{Oa}$ & 14 Feb., & & $\begin{array}{l}\text { Osaka } \\
\text { Pref. }\end{array}$ & $\begin{array}{l}\text { freshly-fallen } \\
\text { snow }\end{array}$ & 2116 & -- & --- & 25.8 & 18.5 & 2.6 & 11.3 & 5.4 & 1.8 & 1.3 & 2.0 & --- & 2.6 & 1) \\
\hline $\mathrm{Ob}$ & & & Univ. & & 2104 & --- & --- & 25.5 & 15.9 & 2.7 & 10.4 & 6.1 & 2.2 & 1.6 & 2.1 & --- & 3.0 & 2) \\
\hline
\end{tabular}

No Hx: No hexane was added to the sample before thawing the sample, and for the others hexane was added to snow sample bottle when snow was collected.

1): Hexane was added in the sampling vat when sampling snow and then thawed. 2) hexane was added after snow was collected in the sampling vat and the thawed.

Detection limit was defined as 3 times as standard deviation of the standard sample with $50 \mu \mathrm{L}$ injection.

ND: below detection limit, ---: not analyzed, under bars: below quantification limits.

sample was placed on clean snow in the upwind area. The polluted snow was exposed to natural sunlight. The dark gray snow turned yellow after ten days, and it was expected that most of the PAHs had photolyzed. Figure 5 shows the degradation of the PAHs on the snow by the sunlight in Antarctica (A10: polluted snow before irradiation; A11: polluted snow after 10 days of irradiation). The PAH concentrations of A10 and A11 were much higher than those of samples A1-A9. The A10 and A11 samples had the average concentrations of 


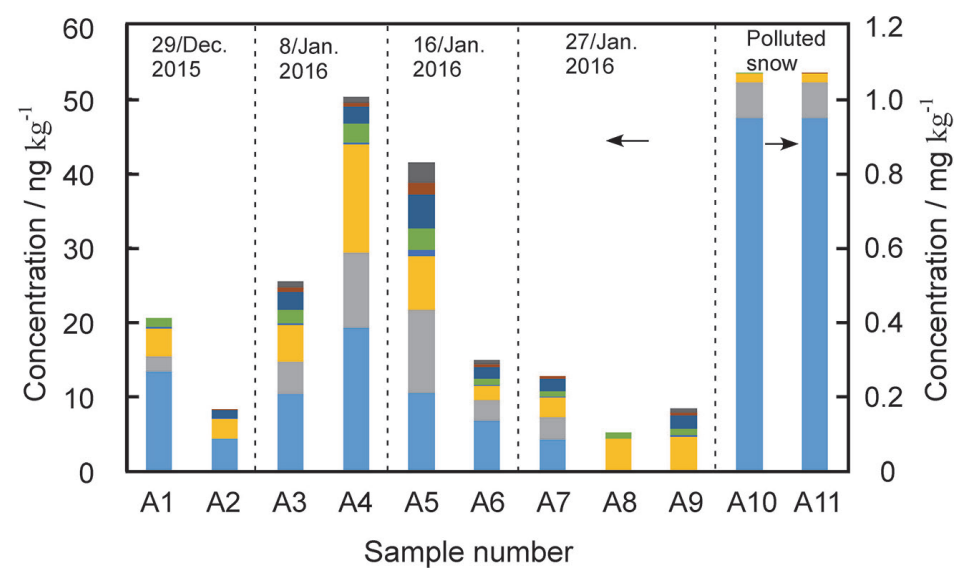

Fig. 5. PAH concentrations in the snow collected at H128 in Antarctica $\square$ Phe, $\square$ AnT, $\square$ Fluo, $\square$ Pyr, $\square$ BaA, $\square$ Chr, $\square$ BbF, $\square$ BkF, $\square$ BaP, $\square$ DahA, $\square$ IndP. A1-A9: left axis, A10 and A11: right axis. Details of A1-A9, see Table 1. A10 and A11: snow polluted by the exhaust gas from the electric generator was collected and set on a clean snow surface on 16 January 2016 (A10, average of 2 samples). The sample was exposed to sunlight and collected on 27 January 2016 (A11, average of 2 samples).

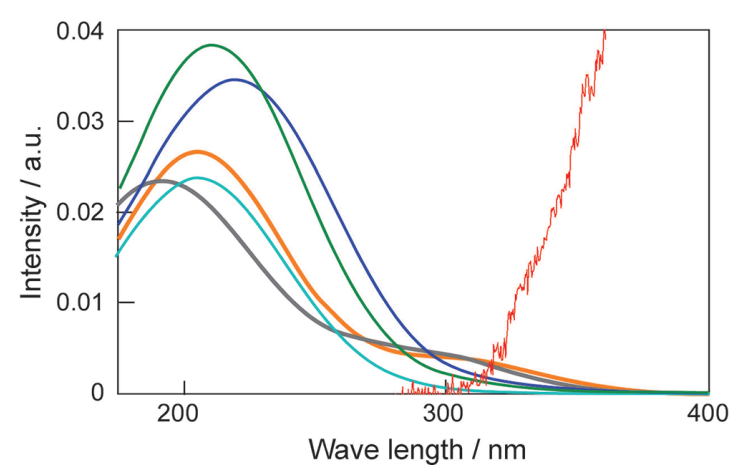

Fig. 6. Absorption spectra of some of the PAHs ${ }^{1}$ and spectrum of solar radiation

—: Phe, — : Fluo, — : Pyr, — : BaA, — : Chr, — : Solar radiation

1: NIST Polycyclic Aromatic Hydrocarbon Structure Index (2019).

ADI and ADF, respectively, in Table 1 and had a comparable concentration and distribution for each PAH. The PAH concentrations in the polluted snow were extremely high and more than hundred thousand times higher than those in normal snow samples. Despite the lighter color in the A11 sample, the concentrations of PAHs did not change very much, as shown in Fig. 5. The lack of photolysis of the PAHs in the snow samples in Antarctica might be a consequence of several reasons. The main reason was the different absorption wavelengths of the PAHs and the spectrum of solar light in Antarctica. The absorption spectra of Phe, Fluo, Pyr, $\mathrm{BaA}$ and $\mathrm{Chr}$ and the emission spectrum (NIST, 2019) of solar radiation measured by an Ocean Optics USB2000+ UV-VIS-ES spectrometer with a TP300-UV/VIS probe at the sampling point are shown in Fig. 6. The solar radiation spectrum started from $300 \mathrm{~nm}$, which agreed with the transmittance of Antarctic snow reported by Beaglehole et al. (1998) (350-900 nm), while the absorbance of the measured PAHs in methanol peaked at approximately $200 \mathrm{~nm}$. Small overlaps between the absorption of the PAHs and the measured solar radiation were observed. The overlap sector of the solar spectrum was supposedly absorbed by certain other organic compounds and colored compounds at high concentrations before reaching the PAHs to induce decomposition. This phenomenon could explain the observed change in color of the snow from dark gray to yellow.

However, the absorbance spectrum of the PAHs in snow might be redshifted, resulting in a larger overlapping area than expected (Kahan and Donaldson et al., 2007). Therefore, other theories should be considered to explain why photolysis of the PAHs in the snow did not occur under Antarctic conditions. In higher-latitude areas, such as Antarctica, PAHs tend to exist in particle form as a result of the temperature effects on the gas-particle equilibrium (Masclet et al., 1988). In the form of particles or fine particles, PAHs are not reactive, which could make the photolysis or photoreaction of PAHs difficult. Moreover, Malley and Kahan (2014) reported the blocking effect of nonchromophoric organic matter on the photolysis of PAHs in ice; however, these compounds were not investigated in this study. In addition, the irradiation time of the polluted snow might not be sufficiently long for the PAHs to decompose. Therefore, further research should be carried out to verify these theories. In summary, the results showed that photolysis was not the main sink of the PAHs in the Antarctic snow.

\section{Conclusion}

The results of this study showed the importance of the preservation methods for analyzing PAHs in snow. Hexane addition must be included in snow sample collection to prevent the evaporation of PAHs after 
sampling and during storage and transport. The time to add hexane should be before collecting the snow sample or soon after collecting the snow sample but thawing should be avoided. The PAH concentrations were lower in the Antarctic snow samples $\left(4.0-7.2 \mathrm{ng} \mathrm{kg} \mathrm{kg}^{-1}\right.$ ) than in the Japanese snow samples (92.3-881.2 $\mathrm{ng} \mathrm{kg}^{-1}$ ) due to the long distance from and low exposure frequency to anthropogenic sources. The results confirmed that the background PAHs in the Antarctic snow contained fewer heavy molecular weight PAHs. The Antarctic snow was heavily polluted by the exhaust of the diesel electric generators used for research activities. High-windspeed events (drifting snow/blizzards) were dilution/scavenging factors of the pollution in snow. Photolysis of the PAHs was not observed after 11 days of sunlight irradiation.

\section{Acknowledgement}

This research is partially supported by Ministry of Education, Culture, Sports, Science and Technology and 57th Japanese Antarctic Research Expedition (JARE57).

\section{References}

Beaglehole, D., Ramanathan, B. and Rumberg, J. (1998): The UV to IR transmittance of Antarctic snow. J. Geophys. Res.: Atmos., 108 (D8), 8849-8867, doi:10.1029/97jd03604.

Carrera, G., Fernández, P., Vilanova, R. M. and Grimalt, J. O. (2001): Persistent organic pollutants in snow from European high mountain areas. Atmos. Environ., 35, 245-254, doi:10.1016/s1352-2310(00)00201-6.

Desideri, P.G., Lepri, L., Checchini, L. and Santianni, D. (1994): Organic compounds in surface and deep Antarctic snow. Int. J. Environ. Anal. Chem., 55, 33-46, doi:10.1080/ 03067319408026207.

Finlayson-Pitts, B. J. and Pitts, J. J. N. (1997): Tropospheric air pollution: ozone, airborne toxics, polycyclic aromatic hydrocarbons and particles. Science, 276, 1045-1051, doi:10.1126/science.276.5315.1045.

Fuoco, R., Giannarelli, S., Onor, M., Ghimenti, S., Abete, C., Termine, M. and Francesconi, S. (2012): A snow/firn fourcentury record of polycyclic aromatic hydrocarbons (PAHs) and polychlorobiphenyls (PCBs) at Talos Dome (Antarctica). Microchem. J., 105, 133-141, doi:10.1016/j.microc.2012.05.018.

Gabrieli, J., Vallelonga, P., Cozzi, G., Gabrielli, P., Gambaro, A., Sigl, M., Decet, F., Schwikowski, M., Gäggeler, H., Boutron, C., Cescon, P. and Barbante, C. (2010): Post 17th-century changes of European PAH emissions recorded in highaltitude alpine snow and ice. Environ. Sci. Technol., 44 (9), 3260-3266, doi:10.1021/es903365s.

Gouin, T., Wilkinson, D., Hummel, S., Meyer, B. and Culley, A. (2010): Polycyclic aromatic hydrocarbons in air and snow from Fairbanks, Alaska. Atmos. Pollut. Res., 1, 9-15, doi:10.5094/apr.2010.002.

Hautala, E. L., Rekilä, R., Tarhanen, J. and Ruuskanen., J. (1995): Deposition of motor vehicle emissions and winter maintenance along roadside assessed by snow analysis. Environ. Pollut., 87, 45-49, doi:10.1016/s0269-7491(99)80006-2.

Hayakawa. K., Tang, N., Nagato E. G., Toriba, A. and Aoki, K. (2019): Identification of Long-range Transported Polycyclic Aromatic Hydrocarbons in Snow at Mt. Tateyama, Japan. Aerosol Air Qual. Res., 19, 1252-1258, doi:10.4209/aaqr.2018. 05.0153 .

Kahan, T. F. and Donalson, D. J. (2007): Photolysis of polycyclic aromatic hydrocarbons on water and ice surfaces. J. Phys. Chem. A, 111, 1277-1285, doi:10.1021/jp066660t.

Kukučka, P., Lammel, G., Dvorská, A., Klánová, J., Möller, A. and Fries, E. (2010): Contamination of Antarctic snow by polycyclic aromatic hydrocarbons dominated by combustion sources in the polar region. Environ. Chem., 7, 504-513, doi:10.1071/en10066.

Li, X. H., Ma, L. L., Liu, X. F., Fu, S., Chen, H. X. and Xu, X. B. (2006): Polycyclic aromatic hydrocarbon in urban soils from Beijing, China. J. Environ. Sci., 18 (5), 944-950, doi.org/10.1016/ S1001-0742(06)60019-3.

Liu, Y., Liu, L., Lin, J.-M., Tang, N. and Hayakawa, K. (2006): Distribution and characterization of polycyclic aromatic hydrocarbon compounds in airborne particulates of east Asia. China Particuology, 4 (6), 283-292, doi:10.1016/s16722515(07)60277-2

Malley, P. P. A. and Kahan, T. F. (2014): Nonchromophoric organic matter suppresses polycyclic aromatic hydrocarbon photolysis in ice and at ice surfaces. J. Phys. Chem. A, 118, 1638-1643, doi:10.1021/jp500263h.

Masclet, P., Pistikopoulos, P., Beyne, S. and Mouvier, G. (1988): Long range transport and gas particle distribution of polycyclic aromatic hydrocarbons at a remote site in Mediterranean Sea. Atmos. Environ., 22, 639-650, doi:10.1016/00046981(88)90002-9

Masclet, P., Hoyau, V., Jaffrezo, J. L. and Cachier, H. (2000): Polycyclic aromatic hydrocarbon deposition on the ice sheet of Greenland. Part I: Superficial snow. Atmos. Environ., 34, 3195-3207, doi:10.1016/s1352-2310(99)00196-x.

Motoyama, H. and N. Hirasawa (2018): H128 Automatic Weather Station (AWS), 1.10, Arctic Data archive System (ADS), Japan, https://ads.nipr.ac.jp/dataset/A20190619-001.

Na, G., Liu, C., Wang, Z., Ge, L., Ma, X. and Yao, Z. (2011): Distribution and characteristic of PAHs in snow of Fildes Peninsula. J. Environ. Sci, 23 (9), 1445-1451, doi:10.1016/ s1001-0742(10) 60605-5.

NIST (2019): NIST Polycyclic Aromatic Hydrocarbon Structure Index, https://pah.nist.gov/?q=pah146, cited on 22 May, 2019.

Rianawati, E. and Balasubramanian, R. (2009): Optimization and validation of solid phase micro-extraction (SPME) method for analysis of polycyclic aromatic hydrocarbons in rainwater and stormwater. Phys. Chem. Earth, Pt $A / B / C$, 34 (13-16), 857-865, doi:10.1016/j.pce.2009.07.003.

Risebrough, R.W., Walker, W.I., Schmidt, T.T., Delappe, B.W. and Connors, C.W. (1976): Transfer of chlorinated biphenyls to Antarctica. Nature, 264, 738-739, doi:10.1038/264738a0.

Tanabe, S., Hidake, H. and Tatsukawa, R. (1983): PCB and chlorinated hydrocarbons pesticides in Antarctic atmosphere and hydrosphere. Chemosphere, 12, 277-288, doi:10.1016/ 0045-6535(83)90171-6.

Thang, P. Q., Taniguchi, T., Nabeshima, Y., Bandow, H., Trung, N. Q. and Takenaka, N. (2014): Distribution of polycyclic aromatic hydrocarbons concentrations simultaneously obtained in gas, rainwater and particles. Air Qual. Atmos. Health, 7 (3), 273-281, doi:10.1007/s11869-013-0234-7.

Vecchiato, M., Argiriadis, E., Zambon, S., Barbante, C., Toscano, G., Gambaro, A. and Piazza, R. (2015): Persistent Organic Pollutants (POPs) in Antarctica : Occurrence in continental and coastal surface snow. Microchem. J., 119, 75-82, doi:10.1016/j.microc.2014.10.010.

Welch., H. E., Muir., D. C. E, Billeck, B. N., Lockhart, W. L., Brunkskill, G. J., Kling, H. J., Olson, M. P. and Lemoine, R. M. (1991): Brow-snow: A long-range transport event in the Canadian Arctic. Environ. Sci. Technol., 25, 280-286, doi:10. 1021/es00014a010.

Yu, B., Xie, X., Ma, L. Q., Kan, H. and Zhou, Q. (2014): Source, distribution, and health risk assessment of polycyclic aromatic hydrocarbons in urban street dust from Tianjin, China. Environ. Sci. Pollut. Res., 21, 2817-2825, doi:10.1007/ s11356-013-2190-z. 